period of years. The Canadian scheme is therefore expected to provide data of vital importance to general studies on atmospheric circulation and in particular to weather forecasting. This development is of special interest to aviation owing to the increased attention that is being given to the possibilities of inter-continental flying by great circle routes passing over the Polar regions. It is understood that the U.S.S.R. are also anxious to increase the number of meteorological stations in their territory within the Arctic Circle. For this purpose, attempts are being made to develop an automatic weather reporting station that would measure and transmit the values of meteorological elements at regular intervals over a long period.

\section{Ice Accretion on Aircraft}

AN interesting series of experiments on the Vickers "Viking" airliner by the British European Airways Corporation in conjunction with Messrs. VickersArmstrong, the designers and makers of the Viking, has been brought to a successful conclusion. It has been established that the building up of ice on parts of an aircraft can be sufficient to force it down, and that the meteorological conditions necessary to cause this may possibly be met on normal everyday flights. Consequently, equipment for dealing with the trouble must be provided on all machines that are expected to carry out flights to arranged schedules and timetables. Methods already tried out for dispersing this ice are : (i) application of heat, (ii) cracking the ice by causing the surfaces to pulsate, (iii) spraying the parts with a de-icing fluid. The latter system was adopted by Messrs. Vickers-Armstrong, and the experimental machine carrying it was flown by the B.E.A.C., as operators of an air transport line, under conditions chosen to be as bad as possible. The system was tried both by allowing ice to accumulate and then dispersing it, and by keeping the apparatus working and preventing the formation of ice. The fluid is sprayed over the wings, tail and control surfaces by means of porous metal distributors inset at the leading edges. It is pumped to these and carried back over the surfaces by the airstream, and is controlled manually by the crew or automatically by an ice detector. Normal flow is on an intermittent pulsation of one 'on' and four 'off' strokes; but in an emergency this can be increased to a continuous flow. To wet the surfaces quickly, when the system is first switched on, the normal intermittent flow is automatically preceded by a short flooding period of continuous pumping.

\section{Pilot Papers}

Pilot Papers, No. 4, is unfortunately not quite up to the standard of previous numbers in point of scientific interest (1, Nov. 1946. Pilot Press, Ltd. 3s. 6d.). The articles are too scattered in subjectmatter and some of them superficial-too long änd too thin-in treatment. The scattering of interest militates against Pilot Papers filling an obvious gap in learned sociological periodicals. Departmental libraries of universities, not to mention university specialists, may well hesitate to subscribe to yet another review for the 'general reader'. One article on the income tax is straight public finance, which is already catered for in economic journals; another is social history in autobiographical form. Two articles, clearly of sociological import, one on the 'squatters', the other on an estate of 'prefabs', are both too long for the common-sense and simple conclusions reached-such as that 'prefabs' are popular; though admittedly data on the 'sense of community' are useful to planners. In particular, the photographs of life among the prefabs might well have been halved without missing the peculiar characteristics of the community. A further article is a popularly written account of progress in psychosomatic medicine. The contribution of perhaps deepest interest deals with the question "Do the Germans Feel Guilty ?" by direct interrogation of Germans.

The introductory 'commentary' by the editor, Mr. Charles Madge, is, however, disarming and certainly makes the best of interpreting the material presented. The comment on several articles is that they add something which journalists have missed. Certainly, they are super-journalism, but in the absence of comparison, generalization and interpretation, this does not qualify the essays as social science, such as Mr. Madge's own commentary certainly is. Pilot Papers have undoubtedly an important part to play in the advancement of the social sciences, at present so backward in Britain. Let us hope future numbers will concentrate more on an anthropological treatment of modern social relations or on comment thereon, less on rapportage, however superior.

\section{Glossaries of Geographical Terms in Different Languages}

THE Royal Geographical Society, through its Committee on Geographical Names for British Official Use, published during the War a number of glossaries of geographical and other terms used on maps of various countries, most of which do not use the Roman alphabet (London: Royal Geographical Society). These glossaries covered Modern Greek, Russian, Albanian, Serbo-Croat and Slovene, Romanian, Siamese and Turkish. The volumes differ a little in scope, but all are glossaries as apart from gazetteers, and they are not concerned with the transliteration of proper names beyond including alphabets and equivalents. Several incorporate new systems of transliteration. Mr. M. Aurousseau, the secretary of the Place Names Committee, contributes to each volume a general article on the writing of geographical names, with a short bibliography on the subject. There are also articles on various linguistic aspects in many of the volumes. The Turkish volume gives both Árabic and Roman script, and the Siamese volume gives both Thai and Roman. These glossaries are invaluable in the utilization of the maps of the countries concerned; nothing else on so comprehensive a scale has been published for a very long time.

\section{Commercial Flower Production}

The Ministry of Agriculture and Fisheries has recently reprinted three booklets on the production of ornamental plants for market. Bulletin No. 109 (London : H.M. Stationery Office. 18.6d. net) deals with summer flowers; Bulletin No. 110 (1s. net) describes the horticulture of plants with decorative foliage; and Bulletin No. 112 (2s. net) considers the treatment of pot plants. All three bulletins have been written by Dr. H. V. Taylor and Dr. Katharine H. Johnstone. A general section on the raising of seedlings appears in each number, and descriptions of the varieties, cultivation and any special technique are given for each species. Length of text for a 